\title{
A Study of Modern Chinese Typological Characteristics From the Perspective of Linguistic Typology
}

\author{
Dan Du \\ Shanghai University of Electric Power, Shanghai, China \\ Wei Chen \\ Zhejiang Gongshang University, Hanghzou Zhejiang, China
}

\begin{abstract}
Based on Greenberg (1965), Dixon (2014), Liu (2017) and Lu and Jin (2015), this article analyzes and interprets the modern Chinese typological characteristics from the perspective of linguistic typology such as the language types, word order type, syntactic type, type of argument configuration, tense-aspect type and so on.
\end{abstract}

Index Terms - linguistic typology, typological characteristics, modern Chinese

\section{INTRODUCTION}

Language typology mainly analyzes linguistic characteristics by large samples in cross-languages in order to explore the implicational universals. The research methods of linguistic typology are mainly to investigate, classify and explain the implicational universals. The purpose of language typology is to explain what implicational universals there are among different language types, what rule systems are behind these implicational universals, and whether these rule systems are applicable to all languages in the world. In this sense, linguistic typology is to pursue and explain the universals, so as to establish a language system with hierarchy, explanatory power and rules. What is a type? A type is a classification of things, and thus a language type is a classification of languages. Why do we divide languages? What are the implications of language classification for language research? There are more than 5000 languages in the world. The classification of languages is for better understanding of languages and explaining certain language phenomena. Since it is a classification, there must be a different classification criteria or perspective. Based on Greenberg (1965), Dixon (2014), Liu (2017) and Lu and Jin (2015), it analyzes and interprets the modern Chinese typological characteristics from the perspective of linguistic typology such as the language types, word order type, syntactic type, type of argument configuration, tense-aspect type and so on.

\section{Typological ChaRACTERISTICS OF LANGUAGE FAMILY}

The branch of linguistics that studies the genealogy of languages and the laws of language differentiation is historical comparative linguistics. According to the historical comparative linguistics researches, it is generally believed language can be divided into a dozen or two dozen languages according to their relationship in the world, there are Sino-Tibetan Family, Indo-European Family, Austroasiatic Family, Austronesian Family, Altaic Family, Bantu Family, Semitic-Hamitic Family and Uralic Family and so on. In addition to the first ten language families, there are more than one hundred small language families scattered around the world, and there are many indigenous languages and primitive tribes that have not been fully understood and recognized by language researchers. Historical linguistics groups all languages from a common original mother tongue into the same family, which is also divided into language families, language branches, languages, dialects, native languages, etc. The subdivision of language families can also be divided into sub-language families, language group, language branch, dialect and sub-dialect.

In terms of speakers, Sino-Tibetan is the second largest language family after Indo-European. It includes Mandarin, the language spoken by the largest number of people in the world. The Sino-Tibetan family is generally divided into four language branches, namely, the Chinese, the Tibeto-Burman, the Dong and the Miao and Yao languages. The Chinese language branch includes languages used by the Han nationality in China. Modern Chinese belongs to the Chinese language family and is the language of the modern Han nationality, including Pu Tong Hua (Mandarin) and different dialects. The Chinese language has ten dialect regions, such as the northern dialect region, the Wu dialect region, the Guangdong dialect region, the Hakka dialect region, the Hunan dialect region, the Gan dialect region, the northern Fujian dialect region, the southern Fujian dialect region, Jin dialect area, Pinghua dialect area. A tonal language usually composed of monophonic words. Words consist of syllables, each of which has a tone. Chinese has four tones, Thai has five, and Cantonese has nine. Many languages belong to isolated languages using function words and word 
order to express syntactic forms. The characteristics of modern Chinese are clearly different from those of the Indo-European languages. In the aspect of pronunciation, there are no consonants, vowels are dominant in syllables, and there are many syllables composed of compound sounds, and the syllables have tones. In terms of vocabulary, the two-syllable words are dominant, and the root compound method is widely used in word formation. In terms of grammar, word order and function words are the main syntactic means, and there is no one-to-one correspondence between the morphology and the sentences. There are also a large number of quantifiers, which are obviously different from the Indo-European languages. Chinese characters are also an important characteristic. The world's oldest writing, apart from Chinese, is the Cuneiform of Mesopotamia and the Hieroglyph of ancient Egypt, but only the Chinese characters have survived. Chinese characters are mainly monosyllabic and have a lot of homophone morphemes. Chinese is the language with the largest population in the world, and there are ten dialect regions at the same time. Although the same morpheme and the same word have different phonetic sounds in different speech regions, their written forms and meanings are the same, which has become a unified communication tool for different dialect regions.

\section{TyPOLOGICAL CHARACTERISTICS OF MORPHOLOGY}

Traditional typology has laid a foundation for the development of language typology. Therefore, when it comes to the types of languages, it is necessary to mention the classification of languages by traditional typology. Traditional typology is classified according to lexical morphology, so they are also called morphological types. In the traditional typology, there are four types of language: inflected language, adhered language, isolated language and multimodal synthetic language. In most cases, Chinese is a typical isolated language, especially ancient Chinese, which expresses syntactic changes through function words and word order. A word is a form. However, there are also flexion forms or adhesive forms in Chinese (Jin Lixin, 2011, p.15). There are also internal inflections in Chinese, which express different syntactic meanings through internal inflections. The word "Hao (好)" has two pronunciations. It is pronounced as an adjective when pronounced as "good". It is pronounced as a verb in castration as "hobby". In Chinese, there are not only internal flexion forms, but also adhesive forms. "Le", "Zhe" and "Guo" have gradually faded from ancient verbs and evolved into modern Chinese tense-aspect markers, such as "Le" is the is the perfect aspect, "Zhe" is the continuous aspect, and "Guo" is the perfective aspect.

And "Number" in the form of a tag, such as "Men(们)" is generally used in can be said after the plural pronouns and noun, such as “Wo/Ni/Ta/Ren(我/你/他/人)” and “Wo/Ni/Ta/Ren Men(我/你/他/人们)”, but it is very limited in which it refers to group concept. Lu put forward the concept of affix according to Modern Chinese syntactic characteristics (1979). Because there are not many real affixes in Chinese, they are not completely evolved in semantics, and sometimes appear in the form of root, such as "Zi(子)", which can be the root "Zi nv (子女 children)" or the quasi-affix “桌子(table)”. “Tou(头)” can be the root “Tou nao (头脑 brain)” or the quasi-affix “Ling tou(领头 leader)” and so on. At the same time, class affixes in Chinese have another feature, which has the function of standard part of speech. For example, “ $\mathrm{Zi}(子)$ )" and “Tou(头)” are used in nouns; “ $\mathrm{Ke}($ 可)” is used in adjectives, such as “Ke ai(可爱 cute)”; "Ran(然)" is used as an adverb, such as “Jing ran(竟然 unexpectedly)"; "Hua(化)” is used as a verb, such as "Mei hua(美化 Beautify)", etc. Although there are inflectional forms and adhesive forms in Chinese, some forms are still in the process of evolution, and the number is still very limited. Compared with the characteristics of isolates, Chinese is still a typical isolated language.

\section{TYPOLOGICAL CHARACTERISTIC OF WORD ORDER}

After the publication of Some universals of grammar with particular reference to the order of meaning Elements by Greenberg, there was a extensive concern of the academic circles, which marked the beginning of the contemporary language typology, and was the history of language typology epochal character. According to the word order between Subject, Verb and Object, Greenberg (1965) roughly divides world languages into six types: SVO, SOV, VSO, VOS, OSV and OVS (p. 25).

According to the diachronic evolution, Shi Yuzhi (2015) believed that the evolution of Chinese word order changed from SVO to a SVO-SOV mixed word order type language. According to ancient Chinese syntactic characteristics such as passive sentences, comparative sentences, tool phrases, word denoting time, adverb phrases, it is considered that ancient Chinese is SVO order (p. 638). And the change of the word order of the southeast dialects is the result of the internal evolution, which is mainly caused by the imbalance of the dynamic and complementary structure in the regional development. Language contact is the external reason, which is mainly caused by the word order change of Northwest dialects caused by the surrounding SOV languages, and it also has some grammatical features of typical SOV language. Finally, in essence, many southern dialects retain more grammatical features of SVO language, while northern dialects gradually deviate from the typical typological features of SVO language due to the influence of the dynamic complement structure. According to the research results of international historical linguistics, human language word order generally evolved from SOV to SVO. Northwest Chinese and Mandarin Chinese provide important adverse examples, in which it evolved into from SVO to SOV under high intensity language exposure, and this adverse development must be compatible with the internal structure of the language. From the synchronic perspective, SVO 
languages often do not have a rich morphological marking system, but mainly rely on analytical means to represent various grammatical categories, and make full use of word order instead of form to identify subject and object. SOV type languages often have a complex morphological marking system, and tend to use morphological means to represent various grammatical categories. They usually use nominative and accusative markers to mark the basic elements of sentences. At the same time, the verbs at the end of sentences in SOV language are often followed by action-related components, such as tense, negative words, energy verbs, etc., which can often become the morphological markers of verbs through the weakening of pronunciation. The structure language has abundant morphological markers of verbs. Whether Chinese is VO word order or OV word order, there is no agreement in the past. Dai (1976) thought it was OV word order. However, $\mathrm{Xu}$ (2004) demonstrated that ancient Chinese used to be a mixed language, and the word order of ancient Chinese was not homogenous, the dominant word order was VO, the OV word order also existed,such as the dominant word order in Oracle is VO, the two word orders VO and OV exist simultaneously. Jin and Yu (2012) believe that Chinese belongs to OV-VO mixed language. Hashimoto Mantaro (1985) believed that the word order of the whole Chinese region from the south to the north of China presented a state of gradual transition from VO to OV. Modern northern Mandarin is mostly influenced by the OV word order of the Altaic language. Jin (2016) believes that the syntactic arrangement of the two coexisting components of Mandarin VO-OV is influenced by northern dialects, while the spoken language of northern progeny is influenced by Altaic family and the mandarin of previous dynasties. Mongolia, Japan and Korea are all OV word order, and there must be a certain influence of national language contact in the communication of the past dynasties.

It is precisely because of the mixed nature of Chinese word order that Chinese also shows a mixed state in the word order of syntactic position, comparative structure, positional adverb, relative clause, functional marker and noun, want verb and tense auxiliary verb related to attached words (Jin and Yu, 2012).

\section{Typological Characteristics of CASE CONFiguration}

According to the characteristics of linguistic case configuration, Dixon (1994) divides the world languages into nominative-accusative languages, absolutive-ergative languages, and spilt-ergative languages. Every language has transitive verbs and intransitive verbs. The transitive verb involves two arguments, labeled A and O; An intransitive verb involves an argument, marked S. How to distinguish the three arguments? Some languages distinguish by syntactic morphology, such as affixes, prepositions, postpositions, case markers, corpusses, pronouns, etc., and some languages distinguish by word order. Chinese verbs belong to nomination-accusative system, and some verbs also belong to absolutive-ergative system (Jin and Wang, 2014). In the Chinese argumentative system, the argumentative system is very similar to the argumentative system, but the difference between them is that the argumentative can move forward when the argumentative system does not appear, while the argumentative syntactic position cannot be moved. And the accusative is preceded and postponed to the verb.

(1) a. 张三打碎了杯子。 b. 杯子打碎了。

(2) a. 中国队打败了美国队。b. 美国队打败了。

According to the above classification system, we can know that “杯子” and “美国队” are absolutive, and the absolutive can move forward when “张三” and “中国队” do not appear.

(3) a. 张三打了李四。 b. *李四打了。

(4) a. 张三照顾了李四。 b. *李四照顾了。

In the above example, the position of the subject and object is fixed, and the position of the object cannot be moved forward. However, according to the syntactic features of Chinese existential sentences, this paper holds that Chinese belongs to a split case system.

(5) a. 台上坐着主席团

b. 主席团坐在台上

(6) a. 村口蹲着一个人

b. 一个人蹲在村口

According to Dixon's subject splitting sentence, it can be seen that in Chinese existential sentences (5) - (6), “主席 团” “一个人”and relative to existential verbs “坐着” “蹲着” still have certain control, so the syntactic function of existential subjects and the agent in intransitive existential verbs is consistent.

(7) a. 黑板上写着几个字。 b. 几个字写在黑板上。

（8）a. 衣服上绣着一朵花。 b. 一朵花绣在衣服上。

In (7) - (8), even if viewed in isolation, if the above sentence is to fill in the missing semantic component, it can only be the agent component. If combined with the context, we can accurately identify the agent. But in existential sentences, none of these agents can be present, otherwise it would not be existential.

(9) 黑板上我写了几个字。

（10）衣服上我绣了一朵花。

From the perspective of subject fluidity and subject splitting, the former and the latter have the same essence, that is, the position of the subject of the intransitive verb can be preceded and postponed, which not only is the absolutive but also is the ergative. In essence, Chinese existential sentences have the feature of splitting case. As can be seen from the above, Chinese belongs to the nominative-accusative, absolutive-ergative, and split-ergative mixed system. 


\section{TyPOlOGiCAl CHARACTERISTICS OF TENSE-ASPECT TYPES}

Human language has the need to express time and motion state. These needs are expressed in different language forms, but different languages have different means to express time and motion state. Lu and Jin (2015) elaborated and demonstrated the types and categories of tense and aspect from the perspective of typology (p.156). Tense refers to the time point when an event takes place relative to a certain reference time, and the expression of time point can be observed through the set time axis. The line segment representing the time axis is composed of countless time points, and different languages have different perceptual sensitivity to time or observation perspectives. Some languages, such as Lithuanian and Kurykh in India, are chronologically divided into past, present and future tense. Some languages, such as Myanmar and Manipur in India, are morphologically divided into two tenses: past and non-past, present and non-present, future and non-future. Some languages have multiple tenses, such as Kenya's Haya and Armenian. In some languages, there is no division of time in Turkish.

The logical classification of "tense" is just an ideal system. In fact, "tense" cannot be neatly divided, and "tense" has no obvious boundary in many languages. Lu and Jin can regard Chinese as a future/non-future type of language only because the degree of grammaticalization of temporal adverbs indicating future is lower than that of future type languages. Although these temporal adverbs can appear in non-future cases, they are not mandatory markers of non-future tense (2015, p.206). Chinese commonly used, for example, “Le(了)”, “Zhe(着)” and “Guo(过)” are tense-aspect markers, “Le(了)” and “Guo(过)” empress the past tense, “Zhe(着)” expresses the present tense, which is visible that it has no future time auxiliary in Chinese, whether or not to speak Chinese will be the future/than the binary language in the future, but a typical/the future in the future, not in the future when using the same kind of mandatory labeling, which is not the case in Chinese. Therefore, whether Chinese can be regarded as the past, present and future trinomial language, but Chinese does not have mandatory trinomial grammatical markers like the trinomial language. It argues that because Chinese is a typical independent language, unlike the inflectional or cohesive languages in the Indo-European family with obvious or mandatory syntactic markers, the division of Chinese tenses does not have an obvious boundary. However, according to the diachronic evolution of time auxiliary verbs, “Le(了)", “Zhe(着)” and “Guo(过)" are all tense auxiliary verbs formed from the constant blurry of common action verbs, among which “Le(了)" and “Guo(过)" represent the past tense. At the same time, in Cantonese and Min dialects, "You(有)" and “Meiyou(没有)” are markers that have evolved from possessive verbs into the present perfect. Therefore, whether the diachronic evolution process of “Le(了)”, “Zhe(着)” and “Guo(过)”, “You(有)” and “Meiyou(没有)” can determine whether Chinese belongs to the dichotomous language of "Present" or "Non-present", but this view needs to be further verified.

Tense category is the reflection of time with verb as the core in cognitive graph. Different languages also have different degrees of perception of the tense. Based on the expression of the tense category in world languages, sums up two forms: "temporal process tense" and "eventual boundary tense" (Lu and Jin 2015, p.174). The temporal process can be divided into present entity and non-present entity, which are internally divided into the proceeding entity (the action is still continuous) and the completion entity (the action has ended). According to the category characteristics of “Le(了)”, “Zhe(着)” and “Guo(过)”, we can know that Chinese belongs to the temporal process tense.
(11) a. 我吃了一个苹果。(吃完了一个苹果)
b. 我吃了一个苹果, 但是没有吃完。
(12) a. 前面坐着位老人。
b. 墙上挂着一幅画。
（13）a. 我去过北京。
b. 我当过老师。

Example (11a) indicates that the action has been completed; in (11b), the action occurred but did not complete; Examples (12a) and (13b) simply mean that the event has been implemented and the action is continuous, not complete, as an existential event that is not over. It can be seen that "Le(了)" does not completely correspond to the end of the behavior, or judge whether the event is complete or incomplete, bounded or unbounded according to the tense markers. It can only judge that the event has become a reality. In Example (13), “Guo(过)" indicates that the event has been realized and is the present entity. Therefore, according to the tense features of “Le(了)", “Zhe(着)” and “Guo(过)”, we can only judge the present entity and non-present entity of time, and we can know that Chinese belongs to temporal process tense rather than eventual boundary tense.

\section{CONCLUSION}

It classifies and summarizes language types from typological perspectives, such as language family, word order type, morphological type, argument configuration type, tense type, etc., and takes modern Chinese as an example to describe the characteristics of Chinese under different language types. Chinese belongs to Sino-Tibetan language family. At the same time, Chinese belongs to isolated language and is a typical SVO-SOV mixed word order. In case configuration, Chinese belongs to nominative - accusative, absolutive - ergative and split case system. From the perspective of tense 
and aspect, Chinese belongs to the dichotomous system.

\section{REFERENCES}

[1] Bingfu Lu, Lixin Jin. (2015). Language Typology Course. Beijing: Peking University Press.

[2] Dan Xu. (2004). Typological Change in Chinese Syntax. Oxford: Oxford Press.

[3] Danqing Liu. (2017). Linguistic Typology. Shanghai: Chinese and Western Book Company.

[4] Dixon R. (1994). Ergativity. Cambridge: CUP.

[5] Greenberg J. H. (1965). Universal of Language. Cambridge: Mass. MIT Press.

[6] Haoyi Dai. (1976). On the Chinese from SVO to SOV in Chinese, in S.B. Steever et al. (eds.), Paper from the Parasession on Diachronic Syntax, CLS, 234-254.

[7] Lixin Jin, Hongwei Wang. (2004). Ergative Case, Absolutive Case and the Classification of Verbs. Foreign Language Teaching and Research, 46(1), 45-57.

[8] Lixin Jin. (2011). What is the linguistic typology? Shanghai: Shanghai Foreign Language Education Press.

[9] Lixin Jin, Xiujin Yu. (2012). Word Order Type of Mandarin Chinese Revisited on Paris of Grammatical Elements Correlated and Uncorrelated with OV-VO. Foreign Languages, 35(3), 22-29.

[10] Lixin Jin. (2016). Typological Evidence and Motivation of Mandarin Mixed Word Order. Chinese Learning, (3), 3-11.

[11] Mantaro Hashimoto. (1985). Geographical Typology of Language. Beijing: Peking University Press.

[12] Shuxiang Lv. (1979). Analysis of Chinese Grammar. Beijing: The Commercial Press.

[13] Yuzhi Shi. (2015). The Grammaticalization of Chinese grammar. Nanchang: Jiangxi Education Press.

Dan Du (b. 1989) is a teacher in Shanghai University of Electric Power. Her research interests include typological linguistics and cognitive linguistics. Her publications include "Typological research on the possession verb and the expression of perfect aspect (2018)", "Typological Characteristics between Existential and Locative Constructions with World Order (2020)" and "Typological Characteristics of Existential Verbs and Tense-Aspect Markers (2021)".

Wei Chen (b. 1988) is a teacher in Zhejiang Gongshang University. His research interests include typological linguistics and cognitive linguistics. His publications include "Analysis Of Asymmetrical Phenomena of Comparative Sentences with 'You'and 'Mei'(2018)", "The Negative Semantic Deviation of 'You +N': an Example of 'You + Wenti'(2019)", and "Semantic Negative Deviation of You and N—-taking you yijian(有意见)as an example(2019)”. 